\title{
(6) OPEN ACCESS \\ Cigarette brands with flavour capsules in the filter: trends in use and brand perceptions among smokers in the USA, Mexico and Australia, 2012-2014
}

\author{
James F Thrasher, ${ }^{1,2}$ Erika N Abad-Vivero, ${ }^{2}$ Crawford Moodie, ${ }^{3}$ Richard J O'Connor, ${ }^{4}$ \\ David Hammond ${ }^{5}{ }^{K}$ Michael Cummings, ${ }^{6}$ Hua-Hie Yong, ${ }^{7}$ Ramzi G Salloum, ${ }^{8}$ \\ Christine Czoli, ${ }^{5}$ Luz Myriam Reynales-Shigematsu ${ }^{2}$
}

For numbered affiliations see end of article.

\section{Correspondence to} Dr James F Thrasher, Department of Health Promotion, Education \& Behavior, Arnold School of Public Health, University of South Carolina, Discovery I Building, 534D, 915 Greene Street, Columbia, SC 29208, USA; thrasher@mailbox.sc.edu

Received 26 September 2014 Accepted 18 February 2015 Published Online First 27 April 2015

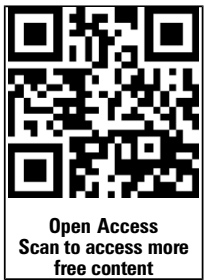

CrossMark

To cite: Thrasher JF, Abad-Vivero EN, Moodie C, et al. Tob Control 2016:25:275-283.

\section{ABSTRACT}

Objective To describe trends, correlates of use and consumer perceptions related to the product design innovation of flavour capsules in cigarette filters. Methods Quarterly surveys from 2012 to 2014 were analysed from an online consumer panel of adult smokers aged 18-64, living in the USA ( $n=6865$ observations; 4154 individuals); Mexico ( $n=5723$ observations; 3366 individuals); and Australia ( $n=5864$ observations; 2710 individuals). Preferred brand varieties were classified by price (ie, premium; discount) and flavour (ie, regular; flavoured without capsule; flavoured with capsule). Participants reported their preferred brand variety's appeal (ie, satisfaction; stylishness), taste (ie, smoothness, intensity), and harm relative to other brands and varieties. GEE models were used to determine time trends and correlates of flavour capsule use, as well as associations between preferred brand characteristics (ie, price stratum, flavour) and perceptions of relative appeal, taste and harm.

Results Preference for flavour capsules increased significantly in Mexico (6\% to $14 \%)$ and Australia ( $1 \%$ to $3 \%$ ), but not in the USA (4\% to 5\%). 18-24 year olds were most likely to prefer capsules in the USA (10\%) and Australia (4\%), but not Mexico. When compared to smokers who preferred regular brands, smokers who preferred brands with capsules viewed their variety of cigarettes as having more positive appeal (all countries), better taste (all countries), and lesser risk (Mexico, USA) than other brand varieties.

Conclusions Results indicate that use of cigarettes with flavour capsules is growing, is associated with misperceptions of relative harm, and differentiates brands in ways that justify regulatory action.

\section{INTRODUCTION}

The tobacco industry has long-used product design characteristics to increase cigarette brand appeal, mislead consumers about health risks and facilitate addiction. $^{1} 2$ One recent product innovation involves flavour capsules in cigarette filters, which consumers can crush at any time to release a burst of flavour. Industry reports highlight the significant growth of the flavour capsule segment of the market; $;^{3-5}$ however, almost no independent research has been conducted to determine the extent of use, to profile users or to understand user perceptions of the product. Research on these topics should inform product regulation, which has generally advanced more slowly than other policy areas promoted by the WHO Framework Convention on Tobacco Control. ${ }^{6}$

\section{Consumer perceptions of flavours and filter technology}

Menthol flavour and filter technology are prominent design features that influence consumer perceptions. Menthol helps retain established smokers by reassuring them about smoking risks, as smokers often perceive menthol cigarettes as less harsh and harmful than regular cigarettes. ${ }^{78}$ Menthol also attracts new smokers, as indicated by the relatively higher prevalence of flavoured cigarette use among youth. ${ }^{9} 10$ Filters reassure consumers about smoking risks. ${ }^{2}$ An increasing number of cigarette brands reference filter 'technology,' which many youth and adults still perceive as reducing harm. ${ }^{11} 12$ However, the way in which flavour capsules in the filter influence consumer perceptions and behaviour is relatively unstudied.

\section{History of flavour capsules}

In the mid-1960s, the American Tobacco Company introduced a cigarette brand with capsules of water in the filter that could be pinched to release moisture and provide a new flavour. ${ }^{13}$ More recently, cigarette filters containing menthol capsules appeared on the Japanese market in 2007, with brand variants featuring capsules now available in most markets. ${ }^{14}$ Capsules typically contain menthol ${ }^{15}$ and can include other often-used tobacco flavourings (eg, sugars, acetaldehyde, levulinic acid, clove). ${ }^{14}$ Spearmint, lemon mint, apple mint and strawberry mint are some of the more recently introduced menthol-related flavours in capsules. ${ }^{16}$ Capsules have been included in flavoured and regular cigarettes, ${ }^{14}$ incorporated into diverse stick sizes (eg, longs, superslims), ${ }^{16} 17$ and some new varieties include two differently flavoured capsules in one filter. Indeed, capsule technology is a key 'premiumisation' strategy for the industry, generating value across price categories. ${ }^{15} 18$

Brands containing flavour capsules are increasingly important for industry growth. ${ }^{3} 414{ }^{18-21}$ For example, a 2011 British American Tobacco (BAT) report describes its capsule brands as reaching the highest share of any innovation across the Americas, with 'low levels of cannibalisation' of its other brands and greatest growth among young adult smokers. ${ }^{4}$ A 2013 Philip Morris International (PMI) report is similarly enthusiastic. ${ }^{3}$ Independent 
focus groups with Scottish women ${ }^{22}$ and industry research ${ }^{23} 24$ indicate the attractiveness of flavour capsules for providing the option of smoking with or without menthol flavouring; being relatively smoother; providing fresher breath; and reducing cigarette odour, making it less obvious that somebody had been smoking. Independent, postmarket quantitative research is needed to better understand patterns of consumer perceptions and use of flavour capsules.

\section{Flavour capsules in the United States, Mexico and Australia}

The present research aims to characterise consumer use and perceptions of capsule brands in three countries (figure 1). In the USA, RJ Reynolds (RJR) first introduced the menthol capsule in 2008 with its 'Camel Crush' variety, and Marlboro followed suit in 2012 with 'Marlboro NXT'. In Mexico, Marlboro capsule varieties were introduced in 2011, with Camel and Pall Mall doing so in 2012. ${ }^{25}$ In 2013, market surveillance in major Mexican cities found 5 varieties of Camel, 3 of Marlboro, and 16 of Pall Mall with a flavour capsule. ${ }^{26}$ Pall Mall is the only international brand in Mexico priced at 'discount' levels. This discount pricing of a relatively high prestige, international brand appears to be an industry response to tax increases. ${ }^{27} 28$ In Australia, flavour capsules were introduced during the lead up to plain packaging implementation in 2012, while package design elements still could be maximised to inform consumers about this design innovation. ${ }^{29}$ While plain packaging prohibited the use of package and product design features to communicate such innovations, flavour capsules themselves were not prohibited.

\section{METHODS}

\section{Study population}

Data came from six quarterly waves of an ongoing study of health warning labels. Adult smokers, aged 18-64, living in Australia, Mexico, and the USA were recruited through online consumer panels provided by Global Market Insite. ${ }^{30}$ At recruitment, eligible participants had smoked at least 100 cigarettes in their lifetime and had smoked at least once in the prior month. Approximately 1000 participants were sampled in each country at each wave, although the US sample included an additional oversample of 400 Latinos to allow for comparisons with Mexico. Quotas were established for age and education groups to obtain a reasonably representative sample in each country. When possible, participants were surveyed at each wave, including participants who had quit. Samples were replenished with eligible smokers at each wave in order to maintain sample size over time.

For the current analysis, six waves of data were analysed for Australia and Mexico (quarterly from September 2012 to May 2014) and five waves from the USA (quarterly from January 2013 to May 2014), for which data collection started onequarter later due to parent project aims. Participants who had quit smoking at the time of the survey were excluded, as preferred brand data were not assessed. The primary analytic sample comprised all current smokers of factory-made cigarettes who provided information on their usual brand.

\section{Measures}

Preferred brand variety

At all waves, smokers identified the brand family for the cigarettes that they usually or currently smoked, after which they were shown images of cigarette packages for brand family varieties on the market at the time of the survey. The brand varieties selected were coded into three categories of flavour (ie, regular non-flavoured cigarettes; flavoured cigarettes, no capsule; flavour capsule) based on analysis of descriptive words in the variety names (eg, menthol; cool; crush) and other marketing messages on the package (eg, 'click on' with a computer symbol for the 'on'). Uncertainties were resolved by Internet searches and/or consultation with in-country expert partners.

Brands were also classified into discount or premium price segments. For Mexico, national brands were classified as discount and international brands as premium, except for Pall Mall, as in prior research. ${ }^{27}{ }^{28}$ For the USA, we classified brands using a scheme developed in prior research that considered price and advertising image, ${ }^{31}$ because both are critical to how the tobacco industry itself promotes premium brands. As such, this coding scheme involved assessment of pricing and tobacco industry representations of brands on industry websites and trade publications. Analyses by price segment were not

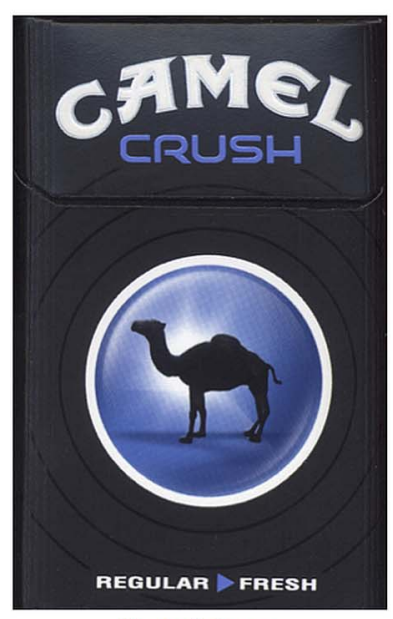

United States

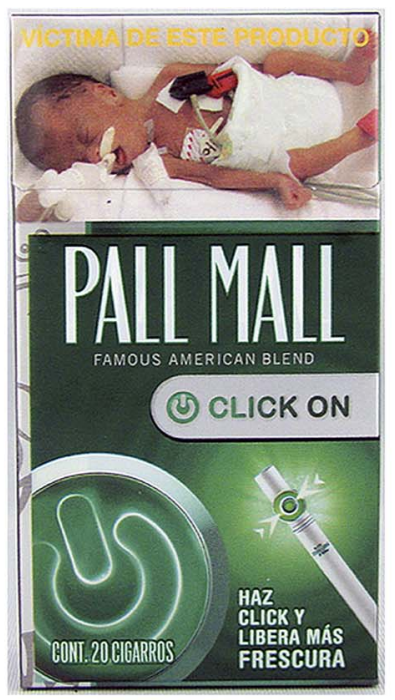

Mexico

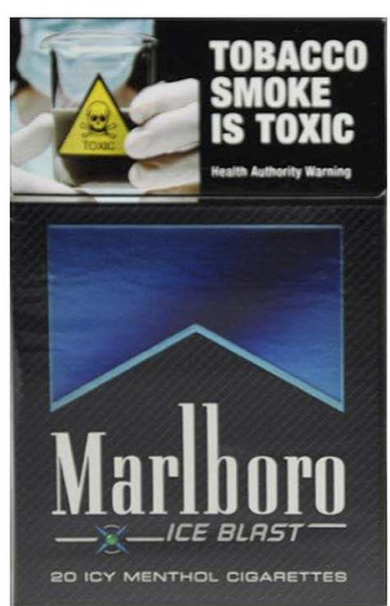

Australia pre-plain packaging

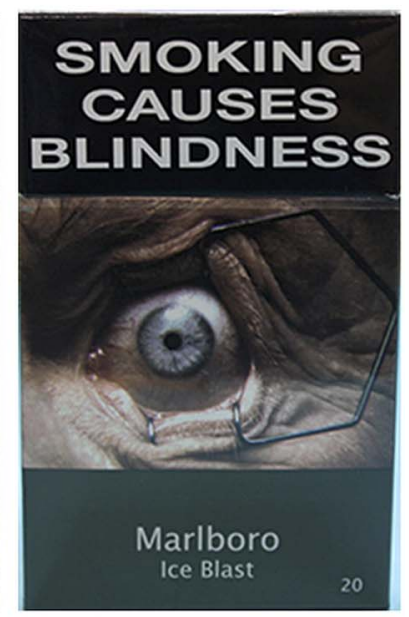

Australia post-plain packaging

Figure 1 Example packages of brand varieties with flavour capsules in the USA, Mexico and Australia, 2014. 
conducted for Australia due to the low number of participants who preferred flavour capsules, price instability over the period after introduction of plain packaging legislation, and difficulties for models convergence. Dummy variables were created for combinations of price category (premium, discount) and flavour (regular cigarettes, flavoured without capsule, or flavour capsule), with regular non-flavoured premium brands as the reference group.

Flavour capsule crushing behaviour

Participants who selected brand varieties with flavour capsules were asked two additional questions in waves V and VI (January 2014 and May 2014, respectively). First, participants were asked "How often do you crush the flavour capsule while you are smoking?" For analysis of correlates of this behaviour, response options (figure $2 \mathrm{~B}$ ) were recoded (ie, always vs less frequent options) due to its non-normal distribution. Next, participants were asked "When do you usually crush the flavour pellet/ capsule?" Again, due to the non-normal distribution of responses, models to determine correlates of the behaviour analysed dichotomised response options (figure 2C) to indicate crushing halfway through the cigarette or later versus crushing earlier.

\section{Brand perceptions}

At each wave, questions on brand perceptions were adapted from tobacco industry protocols. ${ }^{32}$ Participants compared their preferred brand variety with other cigarettes (ie, Compared to other cigarettes, How much is your brand and type of cigarettes?) for relative appeal (ie, more or less satisfying; more or less stylish), taste (ie, lighter or more intense; smoother or harsher), and harm (ie, more or less harmful). Five response options were provided, with no difference as the middle option (eg, much less satisfying; a little less satisfying; the same; a little more satisfying; much more satisfying). Responses were recoded to range from -2 to +2 , with 0 indicating no difference.

\section{Adjustment variables}

Sociodemographic and smoking-related data were collected at each wave. The heaviness of smoking index (HSI) was derived using cigarettes per day and time to first cigarette. ${ }^{33}$ Daily and non-daily smokers were also distinguished, as our sample included many non-daily smokers with low-HSI scores, particularly in Mexico. Recent quit behaviour was assessed by asking participants if they had attempted to quit in the 4 months prior to the survey ( $1=$ 'yes'; $0=$ 'no' or 'don't know'). Quit intentions were also assessed, and the responses were dichotomised to indicate intention to quit in the next 6 months versus not (1='yes'; $0=$ 'no' or 'don't know'). Sociodemographic adjustment variables included age $(18-24 ; 25-34 ; 35-44 ; 45-54 ; 55-64)$, sex (male $=$ reference; female), educational attainment (high school or less; some college or university; complete university or higher), household income (in USA and Australia, annual income: low $=\$ 0-\$ 29999$, middle $=\$ 30000-\$ 59999$, high $=$ $\$ 60000$ or more; in Mexico, monthly income: low $=\$ 0$ $\$ 10000$, middle $=\$ 10001-\$ 20000$, high $=\$ 20001$ or more), and, in the USA, race/ethnicity (Caucasian=reference; AfricanAmerican; Latino; Other). These variables were dummy coded, with the lowest value as the reference group. Dummy variables
Figure 2 (A-C) Prevalence of preference for flavour capsule brand varieties and flavour capsule crushing behavior in the USA, Mexico and Australia.

A

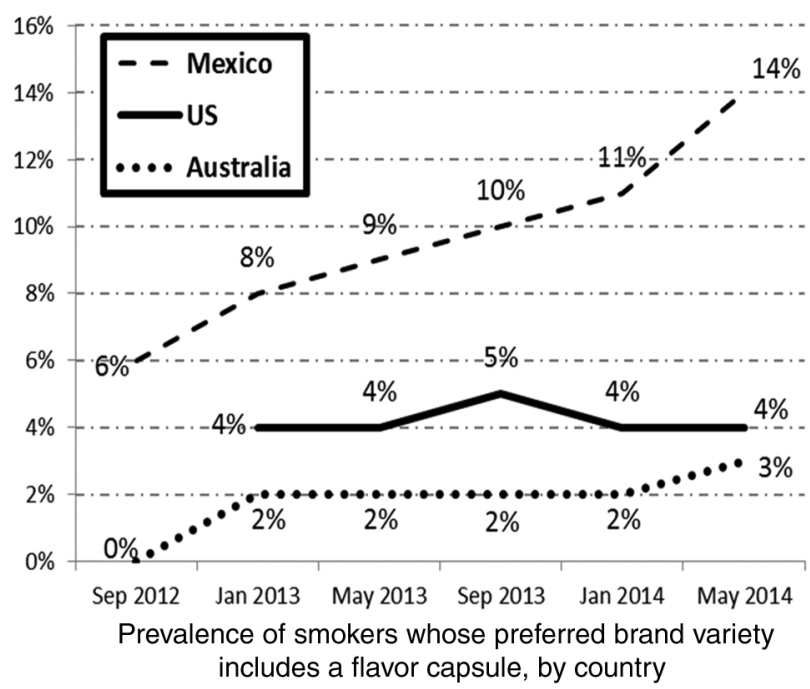

B

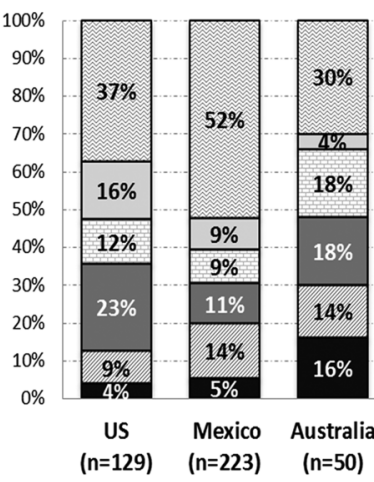

Frequency of crushing flavour capsules amongst users, by country
C

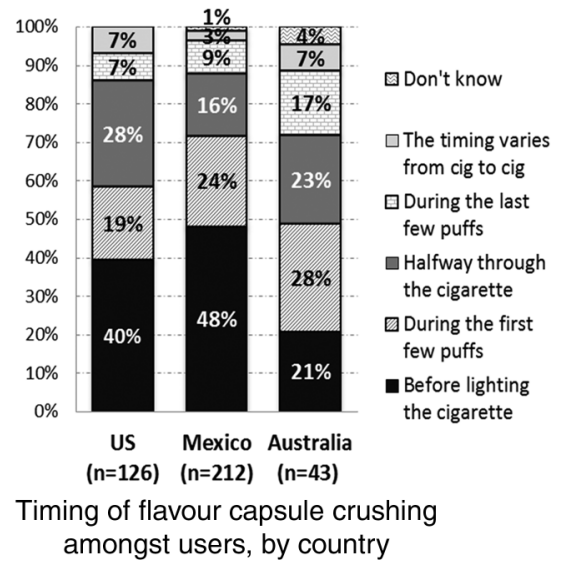


were also created for survey wave and 'time-in-sample,' which adjusts for the number of prior surveys to which a participant responded. Adjustment variables were dummy coded, with the lowest value as the reference group.

\section{Analyses}

Analyses were conducted using STATA/SE 13.1. Descriptive frequencies were assessed for sample characteristics, as well as for the per cent of participants whose capsule varieties clearly indicated menthol flavour and the most popular brand among capsule users. All other frequencies and models were weighted to the age, sex and educational characteristics of the general population of smokers in each country. Country-specific bivariate and adjusted models were estimated for the following outcomes: (1) preference for flavour capsule brands; (2) always crushing the flavour capsule while smoking (flavour capsule users only); (3) crushing the flavour capsule towards the end of the cigarette (flavour capsule users only); (4) perceptions of brand appeal (ie, style, satisfaction), taste (ie, smoothness, lightness), and perceived harm relative to other brand varieties. Generalised estimating equation (GEE) models with binomial distribution and logit link function were estimated for outcomes 1, 2 and 3. GEE models with Gaussian distribution and identity link function were estimated for the fourth set of outcomes. Model results for outcome 2 in Australia are not reported, as models did not converge due to the small sample $(n=110)$. GEE models adjusted for the non-independence of repeated observations through estimation of an exchangeable correlation for repeated observations from participants. Adjusted models included all the adjustment variables described in the measurement section. Predicted probabilities of prevalence for outcome 1 were estimated at each wave for each country using the adjusted model. For models assessing brand perceptions (outcome 4), dummy variables for brand classification by flavour and price tier were also included as independent variables.

\section{RESULTS}

\section{Sample characteristics}

Sample characteristics for all observations over the six waves of data collection are shown in table 1 . When comparing the sample characteristics within each country over time (data available on request), in all three countries, participants with lower educational attainment were less likely to participate in later waves. In the USA and Mexico, participants with lower income were also less likely to participate in later waves. Participants in the USA and Australia who reported recent quit attempts were more likely to participate in later waves, as were daily compared to non-daily smokers. In Australia, women and younger smokers were generally less likely to participate over time.

Across all countries, most flavour capsule varieties referred directly to menthol (eg, menthe, menthol) or used menthol-implied descriptive terms (eg, cool, chill, fresh, freshness, frosted, freeze, ice, mint, refresh, refreshing). Almost all flavour capsule users in the US smoked varieties with these terms (97\%), whereas approximately two-thirds did in Australia (64\%) and Mexico (66\%). The most popular flavour capsule brand was Camel in the USA (96\%), Winfield in Australia (43\%), and Pall Mall in Mexico (78\%).

\section{Time trends and correlates of preference for flavour capsule brands}

Smoker's preference for flavour capsule brands increased over time (see figure 2A) in Mexico (ie, 6\% in 2012 to 14\% in 2014) and Australia (from $0.1 \%$ to $3 \%$ ). By contrast, in the USA,
Table 1 Sample characteristics from all smoker observations in the USA, Mexico and Australia over six waves of data collection, 2012-2014

\begin{tabular}{|c|c|c|c|}
\hline & $\begin{array}{l}\text { USA } \\
(n=6865 / 4154), \\
\%\end{array}$ & $\begin{array}{l}\text { Mexico } \\
(n=5723 / 3366), \\
\%\end{array}$ & $\begin{array}{l}\text { Australia } \\
(n=5864 / 2710), \\
\%\end{array}$ \\
\hline \multicolumn{4}{|l|}{ Age } \\
\hline $18-24$ & 17 & 19 & 8 \\
\hline $25-34$ & 29 & 30 & 24 \\
\hline $35-44$ & 20 & 21 & 22 \\
\hline $45-54$ & 18 & 16 & 23 \\
\hline $54-64$ & 17 & 14 & 23 \\
\hline \multicolumn{4}{|l|}{ Sex } \\
\hline Male & 50 & 55 & 46 \\
\hline Female & 50 & 45 & 54 \\
\hline \multicolumn{4}{|l|}{ Education } \\
\hline$\leq$ High school & 30 & 32 & 34 \\
\hline Some university & 38 & 20 & 41 \\
\hline$\geq$ University & 32 & 49 & 26 \\
\hline \multicolumn{4}{|l|}{ Income } \\
\hline Low & 30 & 40 & 23 \\
\hline Medium & 34 & 33 & 27 \\
\hline High & 36 & 27 & 50 \\
\hline \multicolumn{4}{|l|}{ Race $^{*}$} \\
\hline Caucasian & 52 & & \\
\hline African-American & 5 & NA & NA \\
\hline Latino & 38 & & \\
\hline Other & 4 & & \\
\hline HSI (mean) & 2.2 & 0.8 & 2.7 \\
\hline \multicolumn{4}{|l|}{ Daily smoker } \\
\hline No & 26 & 50 & 15 \\
\hline Yes & 74 & 50 & 85 \\
\hline \multicolumn{4}{|l|}{ Quit intentions } \\
\hline No & 56 & 54 & 57 \\
\hline Yes & 44 & 46 & 43 \\
\hline \multicolumn{4}{|l|}{ Recent quit attempt } \\
\hline No & 57 & 47 & 62 \\
\hline Yes & 43 & 53 & 38 \\
\hline
\end{tabular}

preference for flavoured capsule brands did not change significantly over time (ie, approximately $4 \%$ at each wave). Time-related changes for Mexico and Australia were statistically significant in adjusted models predicting preference for flavour capsule brands (table 2). The individual characteristic most consistently associated with preferring flavour capsule brands across countries was relatively younger age. The only exception was the lack of a statistically significant difference between the youngest and oldest age groups in Mexico, as well as in Australia, but only in the adjusted models. In Mexico and the USA, women were more likely than men to prefer flavour capsule brands. In Australia, smokers with lower HSI were more likely to prefer flavour capsule brands.

\section{Frequency and timing of crushing capsules}

The frequency with which smokers crushed the capsule varied across countries (figure 2B). About half of Mexican smokers $(52 \%)$ reported that they always crushed the capsule, which was higher than in Australia (30\%) and the USA (37\%). In bivariate and adjusted models predicting always crushing the flavour capsule for the USA, women were more likely to always crush 


\begin{tabular}{|c|c|c|c|c|c|c|c|c|c|c|c|c|c|c|c|}
\hline & \multirow[b]{3}{*}{$\%^{*}$} & \multicolumn{4}{|c|}{ USA $(n=6435 / 3919)$} & \multirow[b]{3}{*}{$\%^{*}$} & \multicolumn{4}{|c|}{ Mexico $(n=5442 / 3221)$} & \multirow[b]{3}{*}{$\%^{*}$} & \multicolumn{4}{|c|}{ Australia $(\mathrm{n}=5432 / 2521)$} \\
\hline & & \multicolumn{2}{|c|}{ Bivariate } & \multicolumn{2}{|c|}{ Adjustedt } & & \multicolumn{2}{|c|}{ Bivariate } & \multicolumn{2}{|c|}{ Adjustedt } & & \multicolumn{2}{|c|}{ Bivariate } & \multicolumn{2}{|c|}{ Adjustedt } \\
\hline & & OR & $(95 \% \mathrm{Cl})$ & OR & $(95 \% \mathrm{Cl})$ & & OR & $(95 \% \mathrm{Cl})$ & OR & $(95 \% \mathrm{Cl})$ & & OR & $(95 \% \mathrm{Cl})$ & OR & $(95 \% \mathrm{Cl})$ \\
\hline \multicolumn{16}{|l|}{ Age } \\
\hline $18-24$ & 10 & 1 & & 1 & & 12 & 1 & & 1 & & 4 & 1 & & 1 & \\
\hline $25-34$ & 6 & $0.52^{c}$ & (0.38 to 0.70$)$ & $0.64^{\mathrm{b}}$ & (0.45 to 0.89 ) & 9 & $0.68^{\mathrm{b}}$ & (0.52 to 0.9 ) & $0.66^{\mathrm{b}}$ & (0.49 to 0.88 ) & 3 & 0.81 & (0.41 to 1.61$)$ & 0.82 & (0.37 to 1.84 ) \\
\hline $35-44$ & 3 & $0.28^{c}$ & (0.18 to 0.43$)$ & $0.36^{\mathrm{c}}$ & (0.23 to 0.56$)$ & 7 & $0.61^{\mathrm{b}}$ & (0.44 to 0.84 ) & $0.60^{\mathrm{b}}$ & (0.43 to 0.83 ) & 1 & $0.29^{c}$ & (0.14 to 0.63 ) & $0.32^{c}$ & (0.14 to 0.75$)$ \\
\hline $45-54$ & 2 & $0.13^{c}$ & (0.07 to 0.24$)$ & $0.16^{\mathrm{c}}$ & (0.08 to 0.29 ) & 10 & 0.79 & (0.57 to 1.09 ) & $0.67^{\mathrm{a}}$ & (0.48 to 0.95 ) & 1 & $0.40^{c}$ & (0.18 to 0.88$)$ & 0.48 & (0.19 to 1.23$)$ \\
\hline $55-64$ & 0.4 & $0.07^{c}$ & (0.03 to 0.15$)$ & $0.08^{\mathrm{c}}$ & (0.04 to 0.18 ) & 12 & 0.88 & (0.61 to 1.26 ) & 0.96 & (0.67 to 1.38 ) & 1 & $0.28^{c}$ & (0.12 to 0.68$)$ & 0.43 & (0.16 to 1.10$)$ \\
\hline \multicolumn{16}{|l|}{ Sex } \\
\hline Male & 4 & 1 & & 1 & & 7 & 1 & & 1 & & 1 & 1 & & 1 & \\
\hline Female & 5 & 1.31 & (0.99 to 1.74 ) & $1.39^{\mathrm{a}}$ & (1.03 to 1.88 ) & 13 & $2.02^{\mathrm{C}}$ & (1.62 to 2.52 ) & $2.07^{\mathrm{c}}$ & (1.66 to 2.59$)$ & 2 & 1.39 & (0.89 to 2.19$)$ & 1.52 & (0.91 to 2.52 ) \\
\hline \multicolumn{16}{|l|}{ Education } \\
\hline$\leq$ High school & 4 & 1 & & & & 11 & 1 & & 1 & & 1 & 1 & & 1 & \\
\hline Some university & 5 & 1.11 & (0.8 to 1.52 ) & 0.98 & (0.7 to 1.37 ) & 9 & 0.98 & (0.76 to 1.26 ) & 0.90 & (0.69 to 1.19 ) & 2 & 1.21 & (0.71 to 2.08 ) & 1.05 & (0.60 to 1.84 ) \\
\hline$\geq$ University & 5 & 0.96 & (0.68 to 1.35$)$ & 0.98 & (0.67 to 1.45 ) & 9 & 0.91 & (0.73 to 1.14 ) & 0.85 & (0.66 to 1.09 ) & 3 & $1.96^{\mathrm{c}}$ & (1.13 to 3.39 ) & 1.16 & (0.63 to 2.13$)$ \\
\hline \multicolumn{16}{|l|}{ Income } \\
\hline Low & 4 & & & & & 10 & & & & & 1 & & & & \\
\hline Middle & 5 & 0.97 & (0.66 to 1.42 ) & 1.02 & (0.67 to 1.55 ) & 9 & 0.89 & (0.73 to 1.09 ) & 0.90 & (0.73 to 1.11 ) & 1 & 1.08 & (0.57 to 2.07 ) & 0.93 & (0.48 to 1.82$)$ \\
\hline High & 4 & 0.96 & (0.67 to 1.38 ) & 1.05 & (0.7 to 1.59 ) & 11 & 1.09 & (0.88 to 1.36$)$ & 1.07 & (0.84 to 1.35 ) & 2 & 1.80 & (0.96 to 3.39 ) & 1.52 & (0.77 to 2.99 ) \\
\hline \multicolumn{16}{|l|}{ Race } \\
\hline Caucasian & 4 & 1 & & 1 & & & NA & & & & & NA & & & \\
\hline African-American & 4 & 0.86 & (0.45 to 1.62$)$ & 0.53 & (0.26 to 1.09 ) & & & & & & & & & & \\
\hline Latino & 4 & 0.85 & (0.64 to 1.13 ) & $0.66^{\mathrm{a}}$ & (0.47 to 0.94 ) & & & & & & & & & & \\
\hline Other & 9 & $2.00^{\mathrm{b}}$ & (1.19 to 3.38$)$ & $1.35^{\mathrm{a}}$ & (0.75 to 2.43 ) & & & & & & & & & & \\
\hline HSI & & $0.83^{\mathrm{c}}$ & (0.75 to 0.91 ) & 0.90 & (0.80 to 1.01 ) & & 0.97 & (0.9 to 1.06 ) & 0.94 & (0.86 to 1.03 ) & & $0.78^{c}$ & (0.69 to 0.89 ) & $0.83^{c}$ & (0.71 to 0.96 ) \\
\hline \multicolumn{16}{|l|}{ Daily smoker } \\
\hline No & 6 & 1 & & 1 & & 9 & 1 & & 1 & & 3 & 1 & & 1 & \\
\hline Yes & 4 & $0.65^{b}$ & (0.49 to 0.86 ) & 0.84 & (0.60 to 1.17 ) & 11 & 1.14 & (0.96 to 1.36 ) & $1.24^{\mathrm{a}}$ & (1.02 to 1.51 ) & 2 & $0.61^{c}$ & (0.4 to 0.93 ) & 1.05 & (0.63 to 1.74 ) \\
\hline \multicolumn{16}{|l|}{ Quit intentions } \\
\hline No & 4 & 1 & & 1 & & 11 & 1 & & 1 & & 1 & 1 & & 1 & \\
\hline Yes & 5 & 1.20 & (0.95 to 1.52 ) & 1.11 & (0.82 to 1.49 ) & 9 & 0.89 & (0.75 to 1.05 ) & 0.92 & (0.76 to 1.1 ) & 3 & $1.56^{c}$ & (1.07 to 2.29 ) & 1.35 & (0.87 to 2.09 ) \\
\hline \multicolumn{16}{|l|}{ Quit attempt } \\
\hline No & 4 & & & 1 & & 11 & 1 & & 1 & & 1 & 1 & & 1 & \\
\hline Yes & 5 & 1.22 & (0.96 to 1.55$)$ & 1.04 & (0.77 to 1.41$)$ & 9 & 0.89 & (0.76 to 1.04 ) & 0.89 & (0.75 to 1.07 ) & 3 & $1.65^{c}$ & (1.13 to 2.39 ) & 1.11 & (0.72 to 1.71$)$ \\
\hline Wave & & & & & & & & & & & & & & & \\
\hline 1 & & NA $\ddagger$ & & NA & & 6 & 1 & & 1 & & 1 & 1 & & 1 & \\
\hline 2 & 4 & 1 & & 1 & & 8 & $1.42^{c}$ & (1.10 to 1.86 ) & $1.49^{b}$ & (1.14 to 1.97 ) & 1 & $2.60^{c}$ & (1.22 to 5.58 ) & $3.60^{c}$ & (1.37 to 9.41$)$ \\
\hline 3 & 5 & 1.11 & (0.88 to 1.42$)$ & 1.07 & (0.80 to 1.43 ) & 9 & $1.56^{\mathrm{c}}$ & (1.19 to 2.05 ) & $1.62^{c}$ & (1.22 to 2.15 ) & 2 & $3.29^{c}$ & (1.53 to 7.05 ) & $4.62^{c}$ & (1.76 to 12.13 ) \\
\hline 4 & 6 & 1.28 & (0.98 to 1.67$)$ & 1.17 & (0.84 to 1.63 ) & 11 & $1.79^{c}$ & (1.38 to 2.34 ) & $1.90^{\mathrm{c}}$ & (1.44 to 2.5 ) & 2 & $3.53^{\mathrm{c}}$ & (1.68 to 7.39 ) & $4.34^{c}$ & (1.70 to 11.09 ) \\
\hline 5 & 4 & 0.84 & (0.62 to 1.14$)$ & 0.86 & (0.60 to 1.24 ) & 11 & $1.96^{\mathrm{c}}$ & (1.47 to 2.61 ) & $2.14^{c}$ & (1.59 to 2.88 ) & 2 & $3.37^{c}$ & (1.59 to 7.14 ) & $4.39^{c}$ & (1.69 to 11.41 ) \\
\hline 6 & 4 & 0.75 & (0.54 to 1.05 ) & 0.97 & (0.65 to 1.46 ) & 13 & $2.32^{c}$ & (1.75 to 3.06 ) & $2.60^{\mathrm{c}}$ & (1.94 to 3.47 ) & 3 & $4.92^{\mathrm{c}}$ & (2.36 to 10.26 ) & $5.82^{\mathrm{c}}$ & (2.25 to 15.05 ) \\
\hline
\end{tabular}


than men $(\mathrm{AOR}=4.17,95 \% \mathrm{CI} 1.53$ to $11.36, \mathrm{p}=0.005)$ and those who intended to quit were less likely to always crush $(\mathrm{AOR}=0.21,95 \% \mathrm{CI} 0.08$ to $0.57, \mathrm{p}=0.002)$. No statistically significant correlates were found in the bivariate and adjusted models for Mexico.

Regarding the timing of crushing the capsule (figure $2 \mathrm{C}$ ), the modal response among Mexican and US smokers was 'before lighting the cigarette,' which was similar over time (Mexico $=48 \%$; USA $=40 \%$ ). Timing among Australians appeared more variable, although most smokers still crushed the capsule either before lighting the cigarette $(21 \%)$ or during the first few puffs $(28 \%)$. In bivariate and adjusted GEE models for the USA, sex was the only statistically significant correlate of crushing the capsule after the first few puffs of the cigarette, with a lower likelihood among women than men $(\mathrm{AOR}=0.24,95 \% \mathrm{CI} 0.08$ to $0.72, \mathrm{p}=0.011)$. In models for Mexico, only age was a statistically significant correlate: relatively older smokers were less likely to crush after the first few cigarette puffs than the youngest smokers in both bivariate and adjusted models $\left(\mathrm{AOR}_{25-34}\right.$ vs $18-24=0.17,95 \% \mathrm{CI} 0.06$ to 0.53 , $\mathrm{p}=0.002 ; \mathrm{AOR}_{35-44}$ vs $18-24=0.12,95 \%$ CI 0.03 to 0.44 , $\mathrm{p}=0.001)$. No statistically significant difference was found between the oldest and youngest smokers. For Australia, no independent correlates were found in adjusted models.

\section{Product characteristics and perceived brand attributes}

For US smokers, flavour capsule varieties were only found for premium brands. In bivariate and adjusted models (table 3), US smokers who preferred these varieties were more likely to view their brand as more stylish, smoother and less harmful than people who smoked regular premium brands. The perception that one's preferred brand was lighter in taste was marginally stronger among smokers who preferred flavour capsule premium brands compared to those who preferred regular premium brands, but only in adjusted models $(p=0.09)$.

In bivariate and multivariate models for Mexico, smokers who preferred discount flavour capsule varieties were less likely to report that their brand was more satisfying or more stylish than other brands compared to smokers who preferred regular premium brands (table 3). However, if the preferred capsule variety was a premium price, then Mexican smokers were more likely than those who preferred regular premium brands to report that their variety was more stylish than other cigarettes. Furthermore, in bivariate and adjusted models estimating correlates of relative taste and harm, Mexicans who preferred discount flavour capsule varieties were more likely than regular premium brand smokers to view their brand as smoother, lighter and less harmful. Mexicans who preferred premium flavour capsule varieties were more likely than regular premium brand smokers to view their brand as smoother.

In bivariate and adjusted models for Australia, smokers who preferred flavour capsule varieties were more likely than those who preferred regular brands to state that their variety was more satisfying and smoother than other varieties.

\section{DISCUSSION}

Our study provides further evidence that flavour capsule innovations are important for growing the tobacco market, particularly in Australia and Mexico, consistent with industry reports. ${ }^{3-5} 25$ Industry reports on the market share of flavour capsule brand varieties in 2013 were 2\%, 3\%, 8\% for in Australia, ${ }^{34}$ the $\mathrm{USA}^{35}$ and Mexico, ${ }^{25}$ respectively. These data are consistent with the prevalence estimates for brand preference in our study (ie, 2\%, 4\%, 9\%, respectively), suggesting the external validity of our results.
Similar to other countries, ${ }^{4} 36$ in Mexico, BAT has introduced capsules for at least 16 varieties of Pall Mall, ${ }^{26}$ a global flagship brand; $78 \%$ of Mexicans who smoked flavour capsule cigarettes preferred this brand, which introduced capsules in 2012. Industry analyses have highlighted the rapid growth of the flavour capsule market segment in Mexico, which reached 8\% of sales volume in 2013, just 2 years after its initial introduction. ${ }^{25}$ Filter capsules also may be growing in Australia, where implementation of standardised packaging and marketing bans has limited other brand differentiation strategies. Higher prevalence of use among young adult smokers across countries suggests the importance of this innovation for the future of the industry, which is also consistent with industry research on the importance of novelty for younger people. ${ }^{37}$

The significant rise in flavour capsule popularity in Mexico may be partly due to the availability of flavour capsule varieties in the discount market segment. Indeed, brand switching from higher-priced to lower-priced tobacco products is common in developed markets. ${ }^{38}$ Brand switching likely explains the less apparent age gradient for capsule preference in Mexico compared to Australia and the USA. Hence, the industry can use the flavour capsule to generate value in the discount segment of the market and capture current smokers. In the USA, where only premium brands with capsules are available, no time-related changes in preference for capsules were found, with youth primarily preferring capsule varieties. The fact that capsule cigarettes were introduced in the USA in 2008, and only more recently in Australia and Mexico, may point to the 'novelty' factor wearing off in the USA. However, it is also important to consider the current US regulatory context. The US Food and Drug Administration (FDA) is actively considering prohibition of menthol in cigarettes. Furthermore, the tobacco industry first introduced flavour capsules into the USA market in 2008 and therefore, to stay on the market, would have had to submit to the FDA a 'Substantial Equivalence Report' to prove equivalence of flavour capsules varieties with varieties that were commercially marketed before 2007. Flavour capsule varieties can remain on the market only if the FDA determines that these new products do not have a negative public health impact, including indications that they are do not promote youth smoking or misperceptions about their relative safety. ${ }^{39}$ As far as we are aware, the FDA has yet to issue a verdict on the substantial equivalence of flavour capsules. The tobacco industry may be avoiding the introduction of more flavour capsule varieties and the aggressive marketing found in other countries, because doing so may call the FDA's attention to the negative public health impact of flavour capsules.

Our results suggest that the frequency and timing of crushing flavour capsules vary, within and across countries. The relatively lower frequency of crushing capsules among Australian smokers (30\% never or rarely crush vs $13 \%$ in the US and $19 \%$ in Mexico) may indicate Australian smokers' relative lack of understanding about capsule technology. Indeed, Philip Morris added explanatory descriptors to the plain packaging for its top-selling brand family (ie, 'Blue Regular to Fresh') when the second set of health warnings were rotated onto plain packs in September 2013. However, we found few significant correlates of crushing behaviours within countries, suggesting no clear patterns of use. The exception was in the USA, where women were more likely to always crush the capsule and to do so before or during the first few puffs of a cigarette. This suggests that men are more likely than women to take advantage of the option of smoking with or without the additional flavouring, even though focus groups with young women in Scotland suggested that having 
Table 3 Price segment and flavour characteristics as correlates of relative appeal, taste, and perceived harm of preferred brand variety

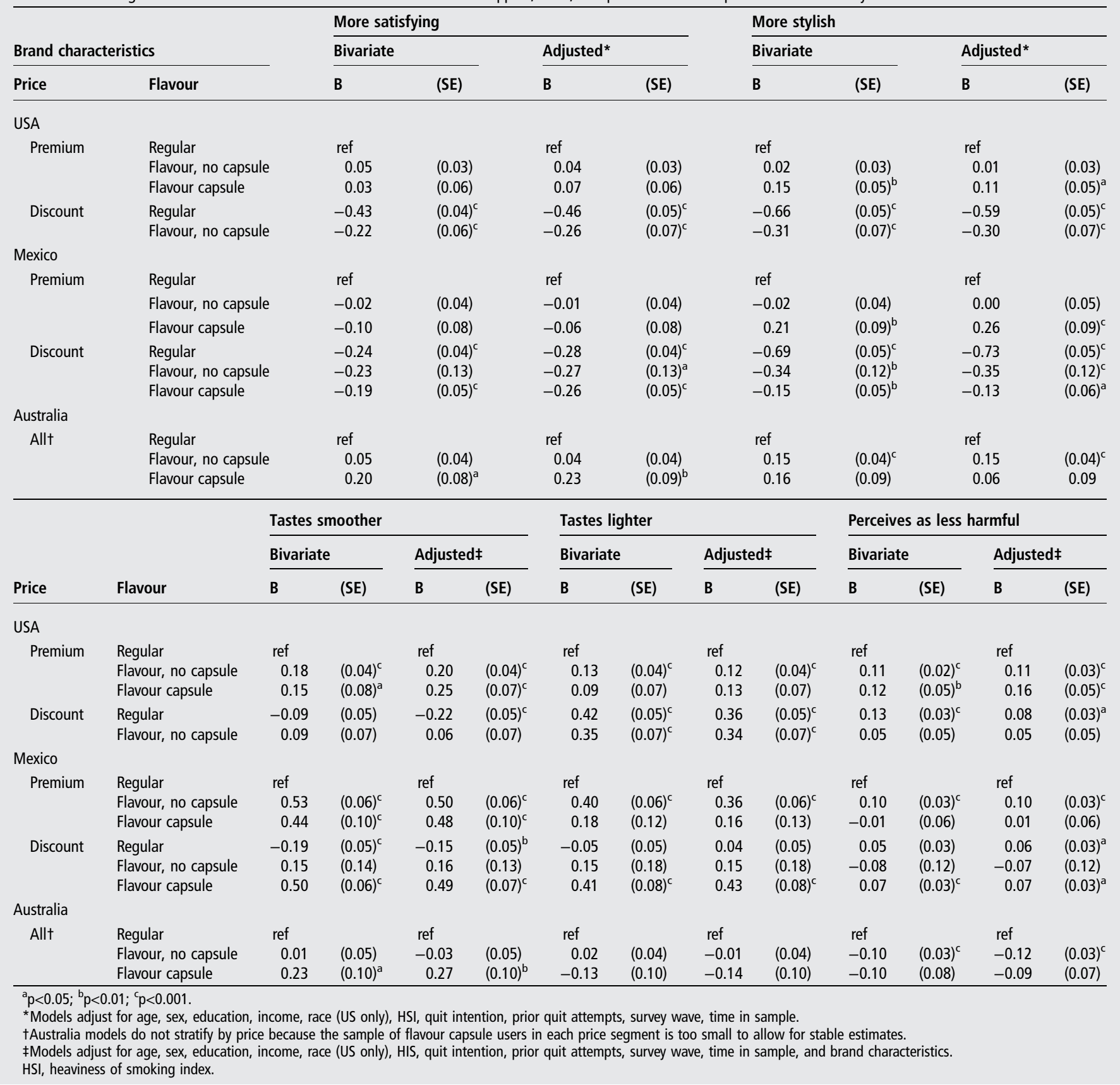

the option was attractive to them. ${ }^{22}$ However, more frequent and earlier crushing of the capsule may be related to other positive attributes that Scottish women and industry premarket testing ${ }^{23}{ }^{24}$ have described, such as less aversive smell, freshening breath and disguising smoke smell from others. Future research should explore these areas of appeal.

In the USA, those who intended to quit were also less likely to always crush the capsule, which may be due to consumer perceptions regarding the addictive properties of flavours. However, one study using Camel $\mathrm{Crush}^{40}$ showed little physiological or smoking behaviour differences with or without the capsule crushed, suggesting that the flavours per se may have little impact on nicotine dose or smokingassociated health risks. Furthermore, an industry-funded paper claimed no '...meaningful increase in the yield of smoke constituents listed by Health Canada as a result of crushing the menthol capsule in the cigarette filter, ${ }^{41}$ Further laboratory, field and qualitative studies may be necessary to understand the contexts for different use behaviours, their psychosocial rationale (eg, perceptions regarding the addictive properties of flavours), and potential biological effects. This research should consider different capsule flavours, including non-menthol flavours, which our study did not address in much detail.

Our results also suggest that the flavour capsule has reinforced brand equity and differentiation in important ways, particularly in Mexico. Mexican smokers who preferred discount flavour capsule brands were more likely than regular premium smokers to view their brand as smoother, lighter and less harmful. It is noteworthy that this pattern is observed despite the fact that capsule users perceived their brand as relatively less satisfying and stylish. Hence, while lower price may disadvantage discount 
brands with regard to perceptions of general appeal, the flavour capsule nevertheless appears to shape key perceptions about product benefits, such as taste and harm. Furthermore, Pall Mall is the only discount brand with flavour capsules, and almost all Pall Mall variants are long $100 \mathrm{~mm}$ sticks and contain capsules. Given the rebirth of Pall Mall as a discount brand in other countries, ${ }^{31}$ future research should further examine whether this product design and price configuration recruits new consumers and impedes cessation in the face of other tobacco control policies.

This study has a number of limitations, including its external validity. The online panel provider that supplied the study sample recruits consumers that are representative of key consumer groups; however, participants come from an unknown sampling frame that is assembled in different ways across countries. Internet penetration is high in the USA and Australia, reducing some concerns about differential participation by populations without Internet access; however, lower Internet penetration in Mexico likely led to over-representation of smokers from higher socioeconomic status groups. Differential attrition also may have biased results, in spite of sample replenishment at each wave. In general, however, changes in sample composition over time were either unassociated with flavour capsule use (eg, income, quit attempts) or they underrepresented subgroups where flavour capsule use is most prevalent (eg, lower participation from younger smokers over time). Our study partly addressed these issues by integrating weights to adjust sample characteristics to sociodemographic profiles of smokers in each country. Future studies with representative samples may be needed to confirm our results, although the general consistency of our study results with industry reports suggests their validity.

Exposing participants to images of brand variants in their preferred brand family may have increased awareness of flavour capsule varieties and thereby promoted their use in subsequent survey waves. This possibility was less likely for US and Mexican participants, who are regularly exposed to brand varieties and package-based advertising at point of sale, than for Australian participants, where cigarette package displays at point of sale are banned. Our adjusted models accounted for 'time in sample' effects, and these effects were not statistically significant predictors of flavour capsule use

\section{What this paper adds}

- Industry reports demonstrate the importance and growth of the market for cigarettes that contain flavour capsules in the filter; however, almost no independent research is available on trends, correlates of use and consumer perceptions related to this innovative product design.

- This paper examined consumer use, profiles and perceptions of flavour capsule cigarettes in three countries: the USA, where the industry appears to have been less aggressive in marketing flavour capsule brands; Mexico, where the industry has introduced discount flavour capsule varieties; and Australia, where flavour capsules can legally differentiate brand variants after plain packaging implementation.

- Flavour capsules are most attractive to youth, although more-established smokers in Mexico also prefer discount capsule varieties. Capsules also differentiate brands and influence consumer perceptions in ways that justify regulatory action. among Australian participants. Also, Australian market reports are consistent with prevalence estimates for 2013. Hence, it is unlikely that the study protocol promoted later flavour capsule use.

In spite of the potential study limitations, our study provides compelling evidence for the growth of flavour capsule brand varieties in key markets, including where marketing regulations are strong (Australia) and where discount capsule brands can offset tax increases and are attractive to younger and older smokers alike (Mexico). Furthermore, consumer perceptions of the benefits of flavour capsule brands, misperceptions of their relative harm, and their appeal among youth suggest that regulation of their use may be justified. Market surveillance should continue, and countries concerned about these issues should consider banning flavour capsules, as will be done in 2016 under the European Union Tobacco Product Directive. $^{42}$

\section{Author affiliations}

${ }^{1}$ Department of Health Promotion, Education \& Behavior, Arnold School of Public Health, University of South Carolina, Columbia, USA

${ }^{2}$ Department of Tobacco Research, Center for Population Health Research, National Institute of Public Health, Cuernavaca, Mexico

${ }^{3}$ University of Stirling, Scotland, UK

${ }^{4}$ Roswell Park Cancer Institute, Buffalo, New York, USA

${ }^{5}$ School of Public Health \& Health Systems, University of Waterloo, Waterloo,

Ontario, Canada

${ }^{6}$ Medical University of South Carolina, Charleston, USA

${ }^{7}$ Cancer Council Victoria, Melbourne, Australia

${ }^{8}$ Department of Health Services Policy \& Management, Arnold School of Public Health, University of South Carolina, Columbia, USA

Contributors JFT, RJOC, DH, KMC and H-HY designed data collection tools and conceptualised the study and analytic approach. ENA-V conducted the statistical analyses and wrote the initial draft of the manuscript with JFT. CM, RJOC, DH, KMC, H-HY, RGS, CC, LMR-S provided substantial contributions to the writing and finalising of the manuscript.

Funding Funding for data collection and analyses was provided by a grant from the USA National Cancer Institute (R01 CA167067).

\section{Competing interests None.}

Ethics approval IRB at University of South Carolina.

Provenance and peer review Not commissioned; externally peer reviewed.

Data sharing statement Additional unpublished data from the study are available by request to the main investigators by email.

Open Access This is an Open Access article distributed in accordance with the Creative Commons Attribution Non Commercial (CC BY-NC 4.0) license, which permits others to distribute, remix, adapt, build upon this work non-commercially, and license their derivative works on different terms, provided the original work is properly cited and the use is non-commercial. See: http://creativecommons.org/ licenses/by-nc/4.0/

\section{REFERENCES}

1 Harris B. The intractable cigarette 'filter problem'. Tob Control 2011;20(Supp 1): i10-16.

2 Pollay R, Dewhirst T. Marketing cigarettes with low machine measured yields. In: Shopland D, Burns D, Benowitz N, et al., eds. Smoking and tobacco control monograph 13: risks associated with smoking cigarettes with low machine-measured yields of tar and nicotine. Bethesda, MD: United States Department of Health and Human Services, 2001:199-233.

3 King M. Investor Day—Latin American \& Canada Region. Lausanne, Switzerland: Phillip Morris International, 2014. https://www.media-server.com/m/instances/ 8hjnb6wm/items/29n825fv/assets/vjr3btkp/0/file.pdf

4 Cobben M. Capsule rollout. Hampshire, United Kingdom: British American Tobacco, 2011. http://www.bat.com/group/sites/UK 8GLKJF.nsf/vwPagesWebLive/ 3FF4B58C81321BC8C12578880056EF37/\$FILE/14_Mark\%20Cobben\%20-\% 20Capsule\%20Rollout.pdf?openelement

5 Hedley D. Game changers and category killers-the tobacco future. Tob J Int 2013;6:33-6.

6 Sweanor D, Yach D. Looking for the next breakthrough in tobacco control and health. S Afr Med J 2013;103:810-11. 
7 Klausner K. Menthol cigarettes and smoking initiation: a tobacco industry perspective. Tob Control 2011;20(S2):ii12-19.

8 Anderson S. Marketing of menthol cigarettes and consumer perceptions: a review of tobacco industry documents. Tob Control 2011;20(S2):ii20-8.

9 Minaker L, Ahmed R, Manske S, et al. Flavored tobacco use among Canadian students in Grades 9-12: prevalence and patterns from the 2010-11 Youth Smoking Survey. Prev Chronic Dis 2014;11:E102.

10 Giovino G, Villanti A, Mowery $P$, et al. Differential trends in cigarette smoking in the USA: is menthol slowing progress? Tob Control 2015;24:28-37.

11 Hammond D, Parkinson C. The impact of cigarette package design on perceptions of risk. East Afr J Public Health 2009;31:345-53.

12 Czoli C, Hammond D. Cigarette packaging: youth perceptions of "natural" cigarettes, filter references, and contraband tobacco. J Adolesc Health 2013;54: 33-9.

13 ATCO. Waterford, the newest taste in cigarettes! American Tobacco Company, 1966. http://news.google.com/newspapers?nid $=888 \&$ dat $=19660415 \&$ id=pxRAAAAIBAJ\&sjid=InQDAAAAIBAJ\&pg=3460,2275459

14 Kahnert S, Pötschke-Langer M, Schunk S, et al. Menthol capsules in cigarette filters -increasing the attractiveness of a harmful product. Heidelberg, Germany: German Cancer Research Center, 2012.

15 Euromonitor International. New product development in cigarettes: innovate or fail - keeping price in power. London: Euromonitor International, 2012. http://www. euromonitor.com/new-product-development-in-cigarettes-innovate-or-fail-keepingprice-in-power/report

16 Tobacco Journal International. KT\&G launches crush-cap ultra-slim. Tob J Int 2013:3:10

17 JTI. JTI introduces Silk Cut SuperSlims Choice. Talking Retail 2014;19 February. http://www.talkingretail.com/products-news/tobacco/jti-introduces-silk-cutsuperslims-choice/

18 MacGuill S. Tobacco control in Chile-an unremarkable market becomes an unlikely bel/wether. Euromonitor International, 2013. http://blog.euromonitor.com/2013/04/ tobacco-control-in-chile-an-unremarkable-market-becomes-an-unlikely-bellwether.html

19 Gilmore $A B$. Understanding the vector in order to plan effective tobacco control policies: an analysis of contemporary tobacco industry materials. Tob Control 2012;21:119-26.

20 Bowles J. Managing the challenges in Western Europe. Hampshire, UK: British American Tobacco, 2011. http://www.bat.com/group/sites/UK__ 8GLKJF.nsf/ vwPagesWebLive/CA0DE1FAF692B52CC12578880058E882/\$FILE/19_Jack\% 20Bowles\%20Managing\%20the\%20Challenges\%20in\%20Western\%20Europe. pdf?openelement

21 Levy J-M. Consumer driven growth. Hampshire, UK; British American Tobacco, 2011. http://www.bat.com/group/sites/UK__8GLKJF.nsf/vwPagesWebLive/ 167002DCAB80D05FC 12578880056CA62/\$FILE/10_Jean-Marc\%20Levy \%20\% 20Consumer\%20driven\%20growth.pdf ?openelement

22 Moodie C, Ford A, Mackintosh A, et al. Are all cigarettes just the same? Female's perceptions of slim, coloured, aromatised and capsule cigarettes. Health Educ Res 2015;30:1-12.

23 Lacy C. Flavor capsule filter: Concept-product test: RJ Reynolds, 2003. http://legacy. library.ucsf.edu/tid/qki06h00;jsessionid=813BBA5B5A5A691B96046B7CFCAE30CF. tobacco04
24 Nuhn R, Smith KC. These are my insights from the crushable capsule focus groups which could work for the Camel family: RJ Reynolds, 2002.

25 Euromonitor International. Cigarettes in Mexico, 2014. http://www.euromonitor. com/cigarettes-in-mexico/report

26 INSP. Referencia: Tobacco Surveillance System TPackSS—Mexico. Cuernavaca, México: Instituto Nacional de Salud Pública, 2013. http://globaltobaccocontrol.org/ tpackss/mexican-products/

27 Saenz de Miera B, Thrasher JF, Chaloupka FJ, et al. Self-reported price, consumption and brand switching of cigarettes in a cohort of Mexican smokers before and after a cigarette tax increase. Tob Control 2010;19:481-7.

28 Saenz de Miera B, Thrasher J, Reynales-Shigematsu L, et al. Tax, price, and cigarette brand preferences: a longitudinal study of adult smokers from the ITC Mexico Survey. Tob Control 2014;23:i80-5.

29 Scollo M, Occleston J, Bayly M, et al. Tobacco product developments coinciding with the implementation of plain packaging in Australia. Tob Control 2014;24(e1): e116-22.

30 GMI. GMI Global Panel Book. Bellevue, WA: Global Market Insight, Inc., 2011.

31 Cornelius ME, Driezen P, Fong GT, et al. Trends in the use of premium and discount cigarette brands: findings from the ITC US Surveys (2002-2011). Tob Control 2014;23:i48-53.

32 Wakefield M, Germain D, Durkin S, et al. Do larger pictorial health warnings diminish the need for plain packaging of cigarettes? Addiction 2012;107:1159-67.

33 Heatherton TF, Koslowski LT, Frecker RC, et al. Measuring the heaviness of smoking using self-reported time to the first cigarette of the day and number of cigarettes smoked per day. Br J Addiction 1989;84:791-800.

34 Euromonitor International. Cigarettes in Australia, 2014. http://www.euromonitor. com/cigarettes-in-australia/report

35 Euromonitor International. Cigarettes in the US, 2014. http://www.euromonitor.com/ cigarettes-in-the-us/report

36 Hegarty R. All Pall Mall cigarettes to be flavour-changers from October. The Grocer 2013; 22 September. http://www.thegrocer.co.uk/fmcg/pall-mall-cigarettes-to-beflavour-changers-from-october/349644.article

37 Wakefield M, Morley C, Horan JK, et al. The cigarette pack as image: new evidence from the tobacco industry documents. Tob Control 2002;11(Supplement i):i73-80.

38 Keynote. Cigarettes \& tobacco market report-2011. London: Keynote, 2011.

39 Leischow S, Zeller M, Backinger C. Research priorities and infrastructure needs of the family smoking prevention and tobacco control act: science to inform FDA policy. Nicotine Tob Res 2012;14:1-6.

40 Strasser A, Ashare R, Kaufman M, et al. The effect of menthol on cigarette smoking behaviors, biomarkers and subjective responses. Cancer Epidemiol Biomarkers Prev 2013;22:382-9.

41 Dolka C, Piadé J, Belushkin $M$, et al. Menthol addition to cigarettes using breakable capsules in the filter: Impact on the mainstream smoke yields of the Health Canada list constituents. Chem Res Toxicol 2013;26:1430-43.

42 European Parliament. Directive 2014/40/EU of the European Parliament and of the Council of 3 April 2014 on the approximation of the laws, regulations and administrative provisions of the Member States concerning the manufacture, presentation and sale of tobacco and related products and repealing Directive 2001/ 37/EC, 2014. http://ec.europa.eu/health/tobacco/docs/dir_201440_en.pdf 